\section{Validity, reliability and \\ understanding of the EORTC-C30 \\ and EORTC-BR23, quality of \\ life questionnaires specific for \\ breast cancer}

Validação, reprodutibilidade e

compreensão do EORTC-C3Oe

EORTC-BR23, questionários de

qualidade de vida específicos para

câncer de mama

\section{Fernanda Alessandra Silva Michels' \\ Maria do Rosario Dias de Oliveira Latorre" \\ Maria do Socorro Maciel'"I \\ 'Coordinator of the Population-Based Cancer Registry of São Paulo, School of Public Health, University of São Paulo, SP, Brazil. \\ "Department of Epidemiology, School of Public Health, University of São Paulo, SP, Brazil. \\ "'Department of Mastology, AC Camargo Cancer Hospital, São Paulo, Brazil.}

Note: Master's Degree scholarship granted by FAPESP (State of São Paulo research Support Foundation) to Fernanda Alessandra Silva Michels - Process 06/57843-6.

Corresponding author: Fernanda Alessandra Silva Michels. Coordenação do Registro de Câncer de Base Populacional de São Paulo, Faculdade de Saúde Pública da Universidade de São Paulo. Av. Dr. Arnaldo, 715 - sala 109, Cerqueira César, 01246-904 São Paulo, SP, Brazil. E-mail: fmichels@usp.br

\section{Abstract}

Objective: To validate and assess reliability and understanding of the EORTC-C30 quality of life questionnaire and its breast cancer specific module, the EORTC-BR23. Methods: This study was conducted at the AC Camargo Cancer Hospital, São Paulo, Brazil. A total of 100 women diagnosed with breast cancer were interviewed. Internal consistency, confirmatory factorial analysis, convergent validity, construct validity and degree of understanding were examined. Reliability was assessed by comparison of means at times 1 and 2, inter-class coefficient and Bland-Altman graphics. Results: Cronbach's alpha ranged from 0.72 to 0.86 for the EORTC-C30 and from 0.78 to 0.83 for the EORTC-BR23 questionnaire. Most questions were confirmed in the confirmatory factorial analysis. In the construct validity analysis, the questionnaires were capable of differentiating patients with or without lymphedema, apart from the symptom scales of both questionnaires. Both questionnaires presented a significant correlation in most domains of the SF-36, in the convergent validity analysis. Only a few criticisms were reported concerning questions, and the mean grade of understanding was high (C30 $=4.91$ and BR23 $=4.89$ ). The questionnaires presented good rates of reliability, with the exception of the functional scale of the C30 and the symptom scale of the BR23. Conclusions: The EORTC-C30 and EORTCBR23 quality of life questionnaires were validated, presented good rates of reliability and are easily understood, allowing them to be used in Brazil to assess quality of life among women with breast cancer.

Keywords: Validation. Reliability. Quality of life. Questionnaire. Breast cancer. Brazil. 


\section{Resumo}

Objetivos: Validar, analisar a reprodutibilidade e avaliar a compreensão do questionário de qualidade de vida EORTC-C30 e seu módulo específico para câncer de mama EORTC-BR23. Métodos: O estudo foi realizado no Hospital do Câncer AC Camargo, São Paulo, Brasil. Foram analisadas 100 mulheres com diagnóstico de câncer de mama. Para validação foi analisada a consistência interna, feita a análise fatorial confirmatória, a validade convergente, a validade de constructo e analisado o grau de compreensão. A reprodutibilidade foi verificada após 2 semanas e foi analisada mediante a comparação de médias, do coeficiente de correlação intraclasse e de gráficos de Bland-Altman. Resultados: $\mathrm{O}$ alfa de Cronbach para o C30 variou de 0,72 a 0,86 e do BR23 de 0,78 e 0,83. Na análise fatorial confirmatória a maioria das questões foi confirmada. Na análise da validade de constructo os questionários foram capazes de discriminar pacientes com ou sem linfedema, com exceção das escalas de sintomas. $\mathrm{Na}$ análise da validade convergente os questionários apresentaram correlação significativa com a maioria dos domínios do SF-36. Os questionários receberam poucas críticas quanto às questões e a média da nota de entendimento foi alta (C30 $=4,91$ e BR23 = 4,89). Os questionários apresentaram bons índices de reprodutibilidade, com exceção da escala funcional do C30 e da escala de sintomas do BR23. Conclusões: Os questionários EORTC-C30 e EORTC-BR23 apresentaram bons índices de validade, de reprodutibilidade e de compreensão, permitindo o seu uso na avaliação da qualidade de vida de brasileiras com câncer de mama.

Palavras-chave: Validação. Reprodutibilidade. Qualidade de vida. Questionário. Câncer de mama. Brasil.

\section{Introduction}

As a result of advances in therapeutics, the number of breast cancer survivors has been increasing substantially in recent decades. According to Lester ${ }^{1}$, the gradual decline in the number of deaths is attributed to the enhancement of techniques for early detection and more effective therapies. The improvement in survival rates has been associated with the concern with quality of life among surviving patients. Quality of life is a subjective and multi-factorial term, interfering in its quantification, even though individuals have the ability to communicate, describe emotions and symptoms ${ }^{2}$.

In 1980 a study group on quality of life was created in the European Organization for Research and Treatment of Cancer (EORTC). Its objective was to develop a short instrument to assess quality of life in international experiments on lung, esophagus and breast cancer ${ }^{3}$. The general quality of life questionnaire is known as EORTC-C30. It is a multidimensional, self-administered questionnaire that consists of 30 questions ${ }^{4}$.

Sprangers et al. ${ }^{5}$ developed a specific module for patients with breast cancer, called EORTC-BR 23, which must be used in combination with the EORTC-C30. The EORTC-BR23 questionnaire has been validated in a number of countries such as Turkey $^{6}$, Singapore ${ }^{7}$, Thailand ${ }^{8}$, Norway ${ }^{9}$, Mexico $^{10}$ among others. According to the European Organization for Research and Treatment of Cancer, this questionnaire has solely one translation into Portuguese, provided by the Institution.

The objectives of the study were to validate and assess reliability and to evaluate the understanding of the EORTC-C30 and EORTC-BR23 quality of life questionnaires among patients with breast cancer in Brazil.

\section{Methods}

The present study was conducted in the AC Camargo Cancer Hospital - Antônio Prudente Foundation. The study population consisted of 100 women, who were 
undergoing routine appointments in the Mastology division of this hospital, aged between 27 and 90 years, diagnosed with breast cancer, treated or in treatment, at any disease stage.

To calculate sample size, population-based studies by Sprangers et al. ${ }^{5}$ and Mosconi et al. ${ }^{11}$ were used as parameter. In these studies, the smallest Cronbach's alpha value was 0.40 . Assuming a type one error $=$ $5 \%$ and power $=90 \%$, it was estimated that 62 patients were necessary to carry out this study.

Following the routine appointment, patients were invited to take part in the research. Once the patient agreed to participate, a written consent was signed. This project was submitted to the approval of the Research Ethics Committee of the AC Camargo Cancer Hospital, under protocol $835 / 06$. Approval was granted on the $26^{\text {th }}$ of September, 2006.

After a brief explanation, a questionnaire containing socio-demographic and clinical characteristics was filled out. Subsequently the EORTC-C30 and EORTC-BR23 questionnaires were presented. Of 100 patients, 92 self-administered the questionnaires while 8 were interviewed by a trained professional.

The EORTC-C30 questionnaire consists of 30 questions and assesses symptoms that occurred in the previous two weeks ${ }^{4}$. Answers are displayed in a Likert scale: 1 not at all, 2 - a little, 3 - quite a bit, 4 - very much; except for the global health scale, which is composed by 2 questions asking patients to classify their general health and quality of life in the previous week, by rating it from 1 to 7 , in which 1 means poor and 7 , excellent. The questionnaires are divided into 3 scales: global health scale (GHS), functional scale (FS) and symptom scale (SS).

The EORTC questionnaire - BR 23 comprises 23 questions (questions 31 to 53), supplementing the general questionnaire. Its answers are also displayed in a Likert scale. This questionnaire contains 2 scales, namely the functional scale and the symptom scale.
The SF-36 questionnaire (Medical Outcomes Study 36-Item Short-Form Health Survey) was employed to assess convergent validity. Due to the inexistence of a specific questionnaire for cancer to serve as gold standard, the SF-36 was chosen for this purpose.

This questionnaire is a generic multi-dimensional instrument to assess quality of life. It is easily administered and understood. It comprises 36 items, grouped into 8 scales: physical functioning, role-physical, bodily pain, general health, vitality, social functioning, role-emotional and mental health ${ }^{12,13}$. This questionnaire was translated into Portuguese by CICONELLI et al. ${ }^{12}$.

After responding to the questionnaire, patients were informed that in two weeks' time they would receive two envelopes at home by mail: one containing the EORTC-C30 and EORTC-BR23 questionnaires and one pre-paid response envelope. Of all patients who were interviewed, 95\% of them sent the reply for the reliability analysis.

The interval between the first and the second interviews to evaluate reliability was 14 days. Marx et $\mathrm{al}^{14}$ showed that there were no statistically significant differences in the test-retest reliability (intra-class correlation coefficient and limits of agreement statistics) for a 2-day interval, as compared with a 2-week interval.

Two methodologies were employed to assess the degree of understanding of the questionnaire and its questions. For individual question assessment, a specific instrument was used. It examined whether the question was difficult to understand, confusing, contained difficult words and/ or was unacceptable.

To verify the degree of understanding of patients in relation to the questionnaire, a verbal-numeric scale adapted from GrassiOliveira et al. ${ }^{15}$, was attached to the end of the questionnaire.

The Cronbach's alpha coefficient was employed to estimate the existing correlation between each questionnaire item and the remaining items or total questionnaire 
score. According to Streiner \& Norman ${ }^{16}$, a questionnaire can be considered to have a good internal consistency when alpha Cronbach's is above 0.70 .

We conducted a confirmatory factor analysis, using the principal component analysis to extract factors, varimax rotation, selection of factors with a KMO (KaiserMeyer-Olkin) $>1$ and correlation coefficient, 0.30 . Only the first factor was accepted. This analysis assumes that the factor structure of a questionnaire is known or hypothetically known a priori. The objective of this analysis is to empirically verify or confirm the factor structure $^{17,18}$. Factor analysis was performed using the Jöreskog \& Moustaki ${ }^{19}$ method to estimate factor models when the variables are qualitative ordinal. In this study, the Lisrel technique was used, which employs the estimated likelihood.

A factor loading was considered good in this study if it was $>0.50$. According to Hair et al. ${ }^{20}$, a factor loading is the correlation of the variable and the factor, the squared loading is the amount of the variable's total variance accounted for by the factor. Although factor loadings from \pm 0.30 to \pm 0.40 are minimally acceptable, values greater than \pm 0.50 are generally considered necessary for practical significance.

In this study, validity was verified by means of construct and convergent validity. In order to observe whether the questionnaire was capable of discriminating different situations ${ }^{8}$, mean scores of women with lymphedema and without it were compared by using the Mann-Whitney test. It is expected that women with lymphedema have a poorer quality of life in comparison with the ones without it.

To verify convergent validity, Spearman correlation coefficients between questionnaires scores and SF-36 domains scores, were calculated in order to examine the capacity of the instrument to correlate in magnitude and direction with the pre-defined hypothesis ${ }^{21}$.

In the present study, to examine questionnaire reliability, the mean scores in both interviews (test and retest) were compared using Wilcoxon test. The intraclass correlation coefficient between two measurements was calculated and accordance between scores (test-retest) was verified by the Bland-Altman method. The interpretation of intraclass correlation followed the recommendation of Landis \& $\mathrm{Koch}^{22}$ : 0.00-0.20, slight; 0.21-0.40, fair; 0.41-0.60, moderate; 0.61-0.80, substantial; and $>0.80$, almost perfect agreement.

Results with $\mathrm{p}$ values below 0.05 were considered statistically significant.

\section{Results}

Women's age ranged from 27 to 90 years (mean: 56.5 years; standard deviation: 12.4 years; median: 54.4 years) and the most frequent age group was $50-59$ years (33\%), followed by the 40-49-year age group (24\%).

About $76 \%$ of patients had access to the Hospital through their health insurance or their own means. Concerning other demographic aspects, $64 \%$ of patients were married, $51 \%$ had completed higher education, $53 \%$ were in full employment at the time of the interview and $69 \%$ were Catholic.

Age at the time of diagnosis varied between 26 and 89 years (mean: 51.6 years; standard deviation: 11.8; median: 50.1 years), and only $12 \%$ had been diagnosed with less than 40 years.

At the time of interview, $48 \%$ of women had been aware of their diagnostic less than two years prior. Mean diagnostic time for this sample was 4.8 years (standard deviation 6.4 years), ranging from 0 to 34 years and median de 2.3 years. In regards to the clinical stage of patients, $38 \%$ of women were in clinical stage I, followed by clinical stage II with $37 \%$. Only one patient had not undergone any type of treatment for cancer and $17 \%$ of women had lymphedema homolateral to the surgery.

The descriptive analyses and internal consistency of questionnaires and their respective scales are described in Table 1.

In the confirmatory factorial analysis of the EORTC-C30 (Table 2), of the 15 questions that comprise the functional scale, 
Table 1 - Descriptive analysis and internal consistency of the EORTC-C30 and EORTC-BR23 questionnaire scales. AC Camargo Cancer Hospital, August to October 2007.

Tabela 1 - Análise descritiva e consistência interna das escalas dos questionários EORTC-C30 e EORTC-BR23. Hospital AC Camargo, agosto a outubro de 2007.

\begin{tabular}{lcccc}
\hline \multicolumn{5}{c}{ Parameter } \\
\hline C30 - Scales & Mean (sd) & Median & Min-max & Cronbach's a \\
Global health & $74.58(19.55)$ & 75.00 & $8.33-100.00$ & 0.72 \\
Functional & $75.64(17.68)$ & 80.00 & $22.22-100.00$ & 0.86 \\
Symptom & $17.51(14.76)$ & 12.82 & $0.00-76.92$ & 0.81 \\
BR23 - Scales & Mean (sd) & Median & Min-max & Cronbach's a \\
Functional & $63.05(18.06)$ & 66.67 & $19.05-91.67$ & 0.78 \\
Symptom & $22.54(16.46)$ & 19.04 & $0.00-71.11$ & 0.83 \\
\hline
\end{tabular}

12 were confirmed. Although explaining $38.58 \%$ of the total variance, they all had correlation coefficients greater than 0.50 . The symptoms scale is comprised of 13 questions, of which nine were selected to compose the factor. All of them contributed to it significantly, since they had a factorial loading above 0.50 .

In the confirmatory factorial analysis of the EORTC-BR23 (Table 2), the two questions that compose the global health scale were selected and both presented heavy factorial loading (above 0.90 ), yet they only explain $16.05 \%$ of the total variance. For the functional scale, a unique factor was defined, which explained $32.56 \%$ of the total variance. Of the eight questions that comprise this scale, five were confirmed by this factor. The factorial solution of only one factor explained $39.49 \%$ of total variance of the symptoms scale. Of the 15 questions that originally compose the scale, eight were confirmed. Although scales had not been confirmed for all questions, we opted to continue analyses with the original scales, because internal consistency was always above 0.70 .

A statistically significant difference for mean scores was observed, with the exception of the symptom scales of both questionnaires. The means of patients with absence of lymphedema were always greater than the means of the other group: the global health scale of the EORTC-C30 (77.11 vs. $62.25, \mathrm{p}=0.003$ ), functional scale of the EORTC-C30 (78.21 vs. 63.14, $\mathrm{p}=0.006$ ), and functional scale of the EORTC-BR23 (64.94 vs. $53.85 \mathrm{p}=0.034$ ). For the symptom scales of questionnaires, in which higher means represent higher levels of symptoms and poorer quality of life, the group with lymphedema had the highest means for the EORTC-C30 (16.62 vs. 21.87, $\mathrm{p}=0.131$ ) and for the EORTC-BR23 (21.16 vs. 29.28, $\mathrm{p}=0.202$ ).

In the convergent validity analysis, the questionnaires were correlated with almost every domain of the SF-36 questionnaire, except for vitality and social aspects domains. Correlation coefficients are described in Table 3 .

In the EORTC-C30 questionnaire, no question was considered difficult and/or unacceptable, only a few questions were identified as confusing. For the EORTCBR23 questionnaire, no questions were described as embarrassing and almost none were regarded as difficult and/or confusing. The mean grade attributed to the understanding of the questionnaire as a whole was 4.91 for the C30 and 4.89 for the BR23.

Only the functional scale of the C30 and the symptom scale of the BR23 had statistically significant differences between scores means, when comparing times 1 and 2 (Table 4).

The Bland-Altman graphs of the C30 and BR23 scales revealed that the questionnaires had a good random distribution around zero, with a few points exceeding limits (Figure 1). 
Table 2 - Confirmatory factorial analysis results of the EORTC-C30 and BR23 questionnaire scales. AC Camargo Cancer Hospital, August to October 2007.

Tabela 2 - Resultados da análise fatorial confirmatória dos domínios dos questionários de qualidade de vida EORTC-C30 e BR23. Hospital AC Camargo, agosto a outubro de 2007.

\begin{tabular}{|c|c|c|c|}
\hline EORTC-C30 & Factor 1 & Variance & Uniqueness \\
\hline \multicolumn{4}{|l|}{ Functional Scale } \\
\hline 1-Do you have any trouble doing strenuous activities? & 0.586 & 0.657 & 0.343 \\
\hline 2-Do you have any trouble taking a long walk? & 0.531 & 0.718 & 0.282 \\
\hline 6-Were you limited in doing either your work or other daily activities? & 0.641 & 0.589 & 0.411 \\
\hline 7-Were you limited in pursuing your hobbies or other leisure time activities? & 0.704 & 0.505 & 0.495 \\
\hline $\begin{array}{l}\text { 20-Have you had difficulty in concentrating on things, like reading a newspaper or watching } \\
\text { television? }\end{array}$ & 0.849 & 0.280 & 0.720 \\
\hline 21-Did you feel tense? & 0.919 & 0.155 & 0.845 \\
\hline 22-Did you feel worried? & 0.924 & 0.146 & 0.854 \\
\hline 23-Did you feel irritable? & 0.911 & 0.170 & 0.830 \\
\hline 24-Did you feel depressed? & 0.926 & 0.143 & 0.857 \\
\hline 25 -Have you had difficulty remembering things? & 0.828 & 0.315 & 0.685 \\
\hline 26-Has your physical condition or medical treatment interfered with your family life? & 0.789 & 0.378 & 0.622 \\
\hline \multirow[t]{2}{*}{ 27-Has your physical condition or medical treatment interfered with your social activities? } & 0.652 & 0.574 & 0.426 \\
\hline & & 4.630 & 7.370 \\
\hline Total variance & & 12.00 & \\
\hline \% Explained variance & & $38.58 \%$ & \\
\hline \multicolumn{4}{|l|}{ Symptoms Scale } \\
\hline 9-Have you had pain? & 0.963 & 0.073 & 0.927 \\
\hline 10-Did you need to rest? & 0.856 & 0.268 & 0.732 \\
\hline 11-Have you had trouble sleeping & 0.670 & 0.552 & 0.448 \\
\hline 12-Have you felt weak? & 0.816 & 0.335 & 0.665 \\
\hline 14-Have you felt nauseated? & 0.786 & 0.382 & 0.618 \\
\hline 16-Have you been constipated? & 0.682 & 0.535 & 0.465 \\
\hline 18-Were you tired? & 0.808 & 0.346 & 0.654 \\
\hline 19-Did pain interfere with your daily activities? & 0.960 & 0.079 & 0.921 \\
\hline \multirow[t]{2}{*}{$\underline{28-H a s ~ y o u r ~ p h y s i c a l ~ c o n d i t i o n ~ o r ~ m e d i c a l ~ t r e a t m e n t ~ c a u s e d ~ y o u ~ f i n a n c i a l ~ d i f f i c u l t i e s ? ~}$} & 0.591 & 0.650 & 0.350 \\
\hline & & 3.220 & 5.780 \\
\hline Total variance & & 9.00 & \\
\hline \% Explained variance & & $35.78 \%$ & \\
\hline \multicolumn{4}{|l|}{ Global Health Scale } \\
\hline 29-How would you rate your overall health during the past week? & 0.901 & 0.187 & 0.813 \\
\hline \multirow[t]{2}{*}{ 30-How would you rate your overall quality of life during the past week? } & 0.931 & 0.134 & 0.866 \\
\hline & & 0.321 & 1.679 \\
\hline Total variance & & 2.00 & \\
\hline$\%$ Explained variance & & $16.05 \%$ & \\
\hline EORTC-BR23 & Factor 1 & Variance & Uniqueness \\
\hline \multicolumn{4}{|l|}{ Functional Scale } \\
\hline 39-Have you felt physically less attractive as a result of your disease or treatment? & 0.966 & 0.067 & 0.933 \\
\hline 40-Have you been feeling less feminine as a result of your disease or treatment? & 0.975 & 0.049 & 0.951 \\
\hline 41-Did you find it difficult to look at yourself naked? & 0.929 & 0.136 & 0.864 \\
\hline 43-Were you worried about your health in the future? & 0.790 & 0.377 & 0.623 \\
\hline \multirow{2}{*}{$\begin{array}{l}\text { 46-Answer this question only if you have been sexually active: to what extent was sex enjoyable } \\
\text { for you? }\end{array}$} & 0.030 & 0.999 & 0.001 \\
\hline & & 1.628 & 3.372 \\
\hline Total variance & & 5.00 & \\
\hline$\%$ Explained variance & & $32.56 \%$ & \\
\hline
\end{tabular}


Table 2 - Confirmatory factorial analysis results of the EORTC-C30 and BR23 questionnaire scales. AC Camargo Cancer Hospital, August to October 2007. (cont.)

Tabela 2 - Resultados da análise fatorial confirmatória dos domínios dos questionários de qualidade de vida EORTC-C30 e BR23. Hospital AC Camargo, agosto a outubro de 2007. (cont.)

\begin{tabular}{|c|c|c|c|}
\hline EORTC-BR23 & Factor 1 & Variance & Uniqueness \\
\hline \multicolumn{4}{|l|}{ Symptoms Scale } \\
\hline 31-Did you have a dry mouth? & 0.460 & 0.789 & 0.211 \\
\hline 35-Answer the question only if you had any hair loss: were you upset by the loss of your hair? & 0.473 & 0.777 & 0.223 \\
\hline 36-Did you feel ill or unwell? & 0.874 & 0.236 & 0.764 \\
\hline 37-Did you have hot flushes? & 0.435 & 0.811 & 0.189 \\
\hline 47-Did you have any pain in your arms or shoulders? & 0.924 & 0.145 & 0.855 \\
\hline 48-Did you have a swollen arm or hand? & 0.960 & 0.078 & 0.922 \\
\hline 49-Was it difficult to raise your arm or to move it sideways? & 0.906 & 0.180 & 0.820 \\
\hline \multirow[t]{2}{*}{ 52-Was the area of your affected breast oversensitive? } & 0.926 & 0.143 & 0.857 \\
\hline & & 3.159 & 4.841 \\
\hline Total variance & & 8.00 & \\
\hline \% Explained variance & & $39.49 \%$ & \\
\hline
\end{tabular}

Table 3 - Spearman coefficient correlation(r) between the EORTC-C30 / BR23 and the SF-36 questionnaires. AC Camargo Cancer Hospital, from August to October 2007.

Tabela 3 - Coeficiente de correlação de Spearman(r) entre os questionários EORTC-C30 / BR23 e o SF-36. Hospital AC Camargo, agosto a outubro de 2007.

\begin{tabular}{lccccc}
\hline \multirow{2}{*}{$\begin{array}{l}\text { Scales } \\
\text { SF-36 }\end{array}$} & $\begin{array}{c}\mathrm{C} 30 \\
\mathrm{GHS}^{*}\end{array}$ & $\begin{array}{c}\mathrm{C} 30 \\
\mathrm{FS}^{*}\end{array}$ & $\begin{array}{c}\mathrm{C} 30 \\
\mathrm{SS}^{+}\end{array}$ & $\begin{array}{c}\mathrm{BR}^{*} \\
\mathrm{FS}^{*}\end{array}$ & $\begin{array}{c}\text { BR23 } \\
\mathrm{SS}^{+}\end{array}$ \\
\cline { 2 - 6 } & $\mathrm{r}(\mathrm{p})^{* * *}$ & $\mathrm{r}(\mathrm{p})^{* * *}$ & $\mathrm{r}(\mathrm{p})^{* * *}$ & $\mathrm{r}(\mathrm{p})^{* * *}$ & $\mathrm{r}(\mathrm{p})^{* * *}$ \\
\hline Physical functioning & $0.28(0.005)$ & $0.47(<0.001)$ & $-0.50(<0.001)$ & $0.42(<0.001)$ & $-0.29(0.003)$ \\
Role-physical & $0.27(0.006)$ & $0.41(<0.001)$ & $-0.37(<0.001)$ & $0.26(0.008)$ & $-0.32(0.001)$ \\
Bodily pain & $-0.49(<0.001)$ & $-0.48(<0.001)$ & $0.56(<0.001)$ & $-0.29(0.004)$ & $0.57(<0.001)$ \\
General Health & $-0.37(<0.001)$ & $-0.24(0.019)$ & $0.19(0.054)$ & $-0.23(0.023)$ & $0.18(0.070)$ \\
Vitality & $0.01(0.962)$ & $-0.01(0.970)$ & $-0.02(0.882)$ & $-019(0.064)$ & $0.04(0.633)$ \\
Social functioning & $-0.13(0.199)$ & $0.03(0.806)$ & $0.11(0.206)$ & $0.05(0.615)$ & $0.09(0.361)$ \\
Role-emotional & $0.35(<0.001)$ & $0.53(<0.001)$ & $-0.36(<0.001)$ & $0.39(<0.001)$ & $-0.23(0.021)$ \\
Mental Health & $0.18(0.081)$ & $0.34(0.001)$ & $-0.29(0.004)$ & $0.18(0.072)$ & $-0.23(0.023)$ \\
\hline
\end{tabular}

* GHS - Global Health Scale / Escala de Saúde Global.

"FS - Functional Scale / EscalaFuncional.

+ SS - Symptom Scale / Escala de Sintomas.

**Results with p values below 0.05 were considered statistically significant./ Resultados com valor de p abaixo de 0,05 foram considerados estatisticamente significativos.

\section{Discussion}

The EORTC-C30 was created to be supplemented with additional modules which examine specific aspects of quality of life for specific groups of patients ${ }^{5}$. Concerning breast cancer, the supplement used is the EORTC-BR23 questionnaire.

Internal consistencies found for general health, functional and symptom scales were $0.72 ; 0.86$ and 0.81 , respectively. Other studies showed similar values, ranging from 0.62 to $0.94^{6-8,10,23}$. For the BR23 module, internal consistencies for functional and symptom scales were 0.78 and 0.83 , respectively. In the study by Sprangers et al. ${ }^{5}$, the lowest values found were in the Spanish sample (between 0.46 and 0.94), while the highest were in the North-American sample $(0.70$ and 0.91$)$. All values obtained for 
Table 4 - Comparison of means of the EORTC-C30 and EORTC-BR23 questionnaires at times 1 and 2 and intraclass correlation coefficient $\left(r_{\text {icc }}\right)$. AC Camargo Cancer Hospital, August to October 2007.

Tabela 4 - Comparação das médias dos questionários EORTC-C30 e EORTC-BR23 nos momentos 1 e 2 e o coeficiente de correlação intraclasse $\left(r_{\text {icc }}\right)$. Hospital AC Camargo, agosto a outubro de 2007.

\begin{tabular}{lcccc}
\hline Scales & $\begin{array}{c}\text { M1 } \\
\text { mean (dp) }\end{array}$ & $\begin{array}{c}\text { M 2 } \\
\text { mean }(d p)\end{array}$ & $p^{*}$ & $r_{\text {icc }}(p)^{* *}$ \\
\hline C30- GHS & $74.91(18.93)$ & $71.49(20.03)$ & 0.064 & $0.45(<0.001)$ \\
C30- FS & $75.77(17.91)$ & $77.87(17.74)$ & 0.040 & $0.76(<0.001)$ \\
C30-SS & $17.98(14.88)$ & $17.19(16.04)$ & 0.275 & $0.75(<0.001)$ \\
BR23 - FS & $63.30(18.39)$ & $63.43(17.93)$ & 0.784 & $0.70(<0.001)$ \\
BR23 - SS & $23.09(16.59)$ & $19.80(15.42)$ & 0.006 & $0.77(<0.001)$ \\
\hline
\end{tabular}

*Wilcoxon test / *Teste de Wilcoxon

**Results with $p$ values below 0.05 were considered statistically significant / **Resultados com valor de p abaixo de 0,05 foram considerados estatisticamente significativos.

Brazilian women fit these patterns. In the study conducted byWAN et al. ${ }^{24}$, Cronbach's alpha was greater than 0.70 in both scales, confirming data shown in this study.

In the confirmatory factorial analysis of the C30 questionnaire, just a few questions were selected to compose the factor of functional and symptom scale, explaining $38.58 \%$ and $35.78 \%$ of total variance, respectively. However, all questions selected greatly contributed to the factor, as they had factorial loading above 0.50 . In the global health scale, the two questions that comprise it, presented factorial loading over 0.90 , but explain just $16.05 \%$ of total variance.

Both BR23 scales had a factorial solution, hence, preserving its original structure. For the functional scale, a single value was defined, which explained $38.25 \%$ of total variance. Questions selected to compose the factor had high factorial loading, with the exception of one question, which showed low weight (0.030). In the symptom scale, eight of the 15 questions which originally comprise the scale were confirmed. They contributed with factorial loading greater than 0.43 . The factorial solution of an isolated factor explained $39.49 \%$ of total variance.

According to Costa ${ }^{18}$, the proposal of a short instrument, considering relevant questions selected in the factorial analysis, must be studied and debated in view of improving psychometric properties of the instrument and also the easiness to apply it. Nevertheless, this study considered that the scale can be maintained, although all questions were not confirmed.

In the construct validity analysis of the C30, general health and functional scales were capable of discriminating groups with presence or absence of lymphedema, demonstrating that patients with this complication present poorer quality of life. However, this was not true for the symptom scale $(p=0.131)$, perhaps due to the fact that this scale is not specific for patients with breast cancer.

Specific studies with C30 did not contemplate lymphedema, since it is a particular complication of breast cancer treatment. In the study performed by Aaronson et al. ${ }^{25}$, C30 was capable of clearly discriminating different groups in terms of general well being, weight loss and treatment toxicity. However, the same questionnaire was not as successful while trying to discriminate patients at different clinical stages.

In the construct validation of BR23, only the functional scale was capable of discriminating groups with or without lymphedema. This may have occurred because the scale, which contains 15 questions, only explores arm morbidity in three questions. With regard to the functional scale, there is a marked difference because this scale employs questions that evidence limitations in the daily life of women brought about by lymphedema. In the research conducted 

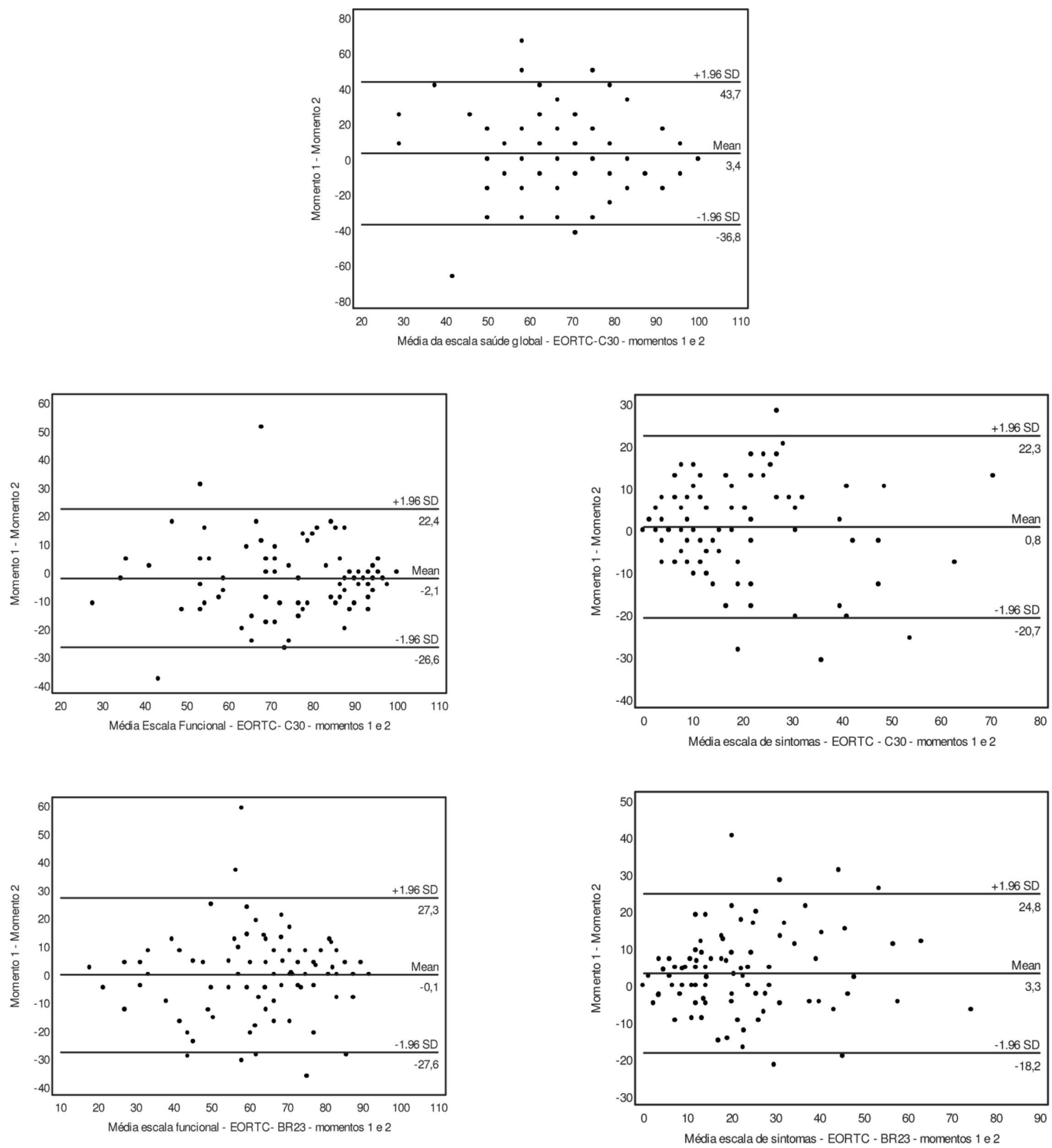

Figure 1 - Bland-Altman graph of scales of the C30 and BR23 questionnaires at times 1 and 2. AC Camargo Cancer Hospital, August to October 2007.

Figura 1 - Gráfico Bland-Altman das escalas dos questionários C30 e BR23 nos momentos 1 e 2. Hospital AC Camargo, agosto a outubro de 2007.

by Alawadhi \& Ohaeri $^{26}$ to assess validity, a group of patients with breast cancer and another group of women without the disease were used. Women in the general population had significantly higher scores than the cancer patients.
In the convergent validation, scores from C30 were moderately correlated with almost all SF-36 domains, excluding vitality and social functioning domains. The C30 and SF-36 questionnaires showed 36 significant correlations for 5 domains (physical 
functioning, bodily pain, vitality, social functioning and mental health) in the study by Fredheim et al. ${ }^{9}$.

Kontodimopoulos et $\mathrm{al}^{27}$ showed that the Spearman's correlations between the C30 and SF-36 scales assessing similar health-related quality of life dimensions ranged from 0.25 to $0.64(\mathrm{p}<0.01)$.These results confirm the hypothesis that in spite of the C30 developed for patients with cancer who have recently undergone treatment, the questionnaire is also capable of measuring health perception of patients, years after this treatment.

The functional scale from BR23 did not have a significant correlation in the convergent validity analysis with vitality, social aspects and mental health domains of the SF-36 questionnaire. The symptom scale did not show a significant correlation with general health status, vitality and social functioning domains. In the study by Wan et al. ${ }^{24}$, the FACT-B questionnaire was employed to verify the correlation with BR23. Of the 5 domains that constitute FACT-B questionnaire, only the domain on family/ social well-being did not have a statistically significant correlation with scales of BR23.

In the reliability analysis, only the functional scale did not achieve similar means at both times. Conversely, Kuenstner et al. ${ }^{28}$ and Hjermstad et al. ${ }^{29}$ found similar means for all scales of the C30 at times 1 and 2 . The functional scale from BR23 showed a statistically significant difference between the two means at times 1 and $2(\mathrm{p}=0.006)$.

Reliability is the consistency of results when the measurement is repeated and it shows the stability of the instrument ${ }^{30}$. However, this method may be affected by many factors, such as the patient remembering and repeating earlier responses; their tendency to avoid repetitiveness, thereby offering new information; and their tendency to report less symptomatology on successive interviews ${ }^{31}$. Our retest took place after two weeks and clinically important changes were not expected to occur within these two weeks. However, as a matter of fact, there will always be methodological uncertainty, because symptoms can be an unstable measurement.

In this study, all questionnaire scales obtained intraclass correlation coefficients from C30 ranging from 0.45 to 0.76 . Values found by Wan et al. ${ }^{24}$ in China varied from 0.65 to 0.89 . Statistically significant values ( $\mathrm{p}<0.001$ ) were found for intraclass correlation coefficients for both functional and symptom scales from BR23, 0.70 and 0.77 , respectively. These were similar to the ones found by Chie et al. ${ }^{32}$.

Using Bland-Altman plots, it was possible to assess the agreement at an individual level, defined as the limit of agreement $( \pm$ $1.96 \mathrm{SD}$ of the mean). Our graphs showed that the points were scattered both above and below zero, indicating no systematic difference between the two moments.

The results found in this study are generally similar to other studies, demonstrating that the EORTC-C30 and EORTC-BR23 questionnaires can be employed to assess quality of life in Brazilian patients with breast cancer.

\section{Conclusion}

The EORTC-C30 / EORTC - BR23 questionnaires showed good internal consistency and demonstrated discriminating capacity for all scales, with the exception of the symptom scale of both instruments.

They were both shown to have good convergent validity in some domains and good reliability, with the exception of the functional scale of the C30 and symptom scale of the BR23. The factorial confirmatory analysis demonstrated that the number of questions can be reduced; nevertheless, this will not be suggested as it would prevent comparison with other studies.

Only a few complaints were reported and the level of understanding was high for both questionnaires.

These results enable the questionnaire to be employed in the assessment of quality of life in Brazilian women with breast cancer.

Conflict of interest: Nothing to declare. 


\section{References}

1. Lester J. Breast cancer in 2007: incidence, risk assessment, and risk reduction strategies. Clin J Oncol Nurs 2007; 11: 619-22.

2. Andritsch E, Dietmaier G, Hofmann G, Zloklikovits S, Samonigg H. Global Quality of Life and its potential predictors in Breast Cancer Patients: an Exploratory Study. Support Care Cancer 2007; 15: 21-30.

3. Bowling A. The concept of quality of life in relation to health. Med Secoli 1995; 7: 633-45.

4. Klee M, Groenvold M, Machin D. Quality of life of danish women: population-based norms for the EORTC QLQ-C30. Qual Life Res 1997; 6(1): 27-34.

5. Sprangers MAG, Groenvold M, Arraras JI et al. The European Organization for Research and Treatment of Cancer Breast Cancer-Specific Quality-of-Life Questionnaire Module: First Results From a ThreeCountry Field Study. J Clin Oncol 1996; 14: 2756-68.

6. Demirci S, Eser E, Ozsaran Z, Tankisi D, Aras AB, Ozaydemir G, Anacak Y. Validation of the Turkish versions of EORTC QLQ-C30 and BR23 modules in breast cancer patients. Asian Pac J Cancer Prev 2011; 12(5): 1283-7.

7. Luo N, Fones CS, Lim SE, Xie F, Thumboo J, Li SC. The European Organization for Research and Treatment of Cancer Quality of Life Questionnaire (EORTC QLQ-c30): validation of English version in Singapore. Qual Life Res 2005; 14: 1181-6.

8. Silpakit C, Sirilerttrakul S, Jirajarus M, Sirisinha T, Sirachainan E, Ratanatharathorn V. The European Organization for Research and Treatment of Cancer Quality of Life Questionnaire (EORTC QLQ-C30): validation study of the Thai version. Qual Life Res 2006; 15: 167-72.

9. Fredheim OM, Borchgrevink PC, Saltnes T, Kaasa $\mathrm{S}$. Validation and comparison of the health-related quality-of-life instruments EORTC QLQ-C30 and SF-36 in assessment of patients with chronic non malignant pain. J Pain Symptom Manage 2007; 34: 657-65.

10. Cerezo O, Oñate-Ocaña LF, Arrieta-Joffe P, GonzálezLara F et al. Validation of the Mexican-Spanish version of the EORTC QLQ-C30 and BR23 questionnaires to assess health-related quality of life in Mexican women with breast cancer. Eur J Cancer Care (Engl) 2012; 21(5): 68491.

11. Mosconi P, Torri V, Cifani S, et al. The Multi-Center Assessment of Quality of Life: The Interdisciplinary Group for Cancer Care Evaluation (GIVIO) Experience in Italy. Stat Med 1998; 17: 577-85.

12. Ciconelli RM, Ferraz MB, Santos W, Meinão I, Quaresma MR. Tradução para a Língua Portuguesa e Validação do Questionário Genérico de Avaliação de Qualidade de Vida SF-36 (Brasil SF-36). Rev Bras Reumatol 1999; 39: 143-50.
13. Castro M, Caiuby AVS, Draibe AS, Canziani MEF. Qualidade de vida de pacientes com insuficiência renal crônica em hemodiálise avaliada através do instrumento genérico SF-36. Rev Assoc Med Bras 2003; 49: 245-9.

14. Marx RG, Menezes A, Horovitz L, Jones EC, Warren RF. A comparison of two time intervals for test-retest reliability of health status instruments. J Clin Epidemiol 2003; 56(8): 730-5.

15. Grassi-Oliveira R, Stein LC. Tradução e validação de conteúdo da versão em português do childhood trauma questionnaire. Rev Saúde Pública 2006; 40: 249-55.

16. Streiner DL, Norman GR. Health measurement scales: $a$ pratical guide to their development and use. 3 ed. Oxford: Oxford University Press; 2003. Validity; p. 172-193.

17. Sharma S. Applied multivariate techniques. New York: Jonh Wiley e Sons; 1996. Factor Analysis, p. 90-143.

18. Costa LS. Qualidade de vida em crianças e adolescentes com HIVIAIDS: validação e reprodutibilidade de instrumentos (tese de doutorado). São Paulo: Faculdade de Saúde Pública da Universidade de São Paulo; 2007.

19. Jöreskog KG, Moustaki I. Factor analysis of ordinal variables with full information maximum likelihood. 2006. Available at http://www.ssicentral.com/lisrel/ techdocs/orfiml.pdf (Acessed Mar 27, 2012).

20. Hair, J.F., Anderson, R.E., Tatham, R.L., \& Black, W.C. (1998). Multivariate Data Analysis (5 ${ }^{\text {th }}$ Edition). Upper Saddle River, NJ: Prentice Hall.

21. De Boer JB, Van Dam FSAM, Sprangers MAG. Healthrelated quality-of-life evaluation in HIV-infected patients. Pharmaco Economics 1995; 8: 291-304.

22. Landis JR, Koch GG. The measurement of observer agreement for categorical data. Biometrics 1977; 33(1): 159-74.

23. Kemmler G, Holzner B, Kopp M et al. Comparison of two quality-of-life instruments for cancer patients: the functional assessment of cancer therapy-general and the European Organization for Research and Treatment of Cancer Quality of Life Questionnaire-C30. J Clin Oncol 1999; 17: 2932-40.

24. Wan C, Tang X, Tu XM, et al. Psychometric properties of the simplified Chinese version of the EORTC QLQ-BR53 for measuring quality of life for breast cancer patients. Breast Cancer Res Treat 2007a; 105: 187-93.

25. Aaronson NK, Ahmedzai S, Bergman B et al. The European Organization for Research and Treatment of Cancer QLQ-C30: a quality-of-life instrument for use in international clinical trials in oncology. J Natl Cancer Inst 1993; 85: 365-76. 
26. Alawadhi SA, Ohaeri JU. Validity and reliability of the European Organization for Research and Treatment in Cancer Quality of Life Questionnaire (EORTC QLQ): experience from Kuwait using a sample of women with breast cancer. Ann Saudi Med 2010; 30(5): 390-6.

27. Kontodimopoulos N, Ntinoulis K, Niakas D. Validity of the Greek EORTC QLQ-C30 and QLQ-BR23 for measuring health-related quality of life in breast cancer patients. Eur J Cancer Care (Engl) 2011; 20(3): 354-61.

28. Kuenstner S, Langelotz C, Budach V, Possinger K, Krause $\mathrm{B}$, Sezer O. The comparability of quality of life scores a multitrait multimethod analysis of the EORTC QLQC30, SF36 and FLIC questionnaires. Eur J Cancer 2002; 38: 339-48.

29. Hjermstad MJ, Fossa SD, Bjordal K, Kaasa S. Test/retest study of the European Organization for Research and Treatment of Cancer Core Quality-of-Life Questionnaire. J Clin Oncol 1995; 13: 1249-54.
30. Pereira MG. Epidemiologia: teoria e prática. Rio de Janeiro: Guanabara Koogan; 2006. Aferição dos eventos; p. 358-76.

31. Bakker IM, Terluin B, van Marwijk HW, van Mechelen W, Stalman WA. Test-retest reliability of the PRIME-MD: limitations in diagnosing mental disorders in primary care. Eur J Public Health 2009; 19(3): 303-7.

32. Chie WC, Chang KJ, Huang CS, Kuo WH. Quality of life of breast cancer patients in Taiwan: validation of the Taiwan Chinese version of the EORTC QLQ-C30 and EORTC QLQ-BR23. Psychooncology 2003; 12: 729-35.

Recebido em: 27/03/12 Versão final apresentada em: 04/09/12 Aprovado em: 31/10/12 